\title{
Programmable intrathecal pumps for the management of chronic pain: recommendations for improved efficiency
}

This article was published in the following Dove Press journal:

Journal of Pain Research

3 October 2014

Number of times this article has been viewed

\section{Denise Wilkes}

Department of Anesthesiology and Pain Medicine, University of Texas Medical Branch, Galveston, TX, USA
Correspondence: Denise Wilkes Department of Anesthesiology and Pain Medicine, University of Texas Medical Branch, 30I University Blvd, Galveston, TX 77555, USA

Email dwilkes@utmb.edu
Abstract: The management of chronic pain can be very challenging. Often, physicians employ intrathecal (IT) drug delivery systems as a last resort to relieve intractable pain. The system consists of an implantable pump that stores and delivers medication through a catheter to the IT space. Programmability is achieved by positioning an external devise over the implanted pump to change the mode of drug delivery. The innovations in programmable IT drug delivery systems are expanding more rapidly than ever before. Unfortunately, the rapid expansion is accompanied by a lack of prospective randomized trials examining these new options. In an effort to improve results and reduce side effects, publications by experts or expert consensus panels provide guidance for the community. The purpose of this article is to provide a summary of high interest topics in recent publications.

Keywords: intrathecal morphine, chronic pain, programmable drug delivery, implantable drug delivery

\section{Introduction}

Analgesia can be administered by many different routes such as oral, intravenous, subcutaneous, transdermal, transmucosal, and intrathecal (IT). Long-term management of chronic non-cancer pain is mainly accomplished with oral analgesics. After many years of continuous oral analgesics, the daily dose can escalate to a point of intolerable side effects or ineffective pain control. Many studies have suggested techniques to restore analgesia such as opioid rotation or opioid holiday. But in $10 \%-30 \%$ of patients treated for chronic pain, they fail to obtain adequate analgesia with oral analgesics. ${ }^{1}$ The American Society of Interventional Pain Physicians recommends IT analgesia route "after all other methods have failed including conservative and surgical treatment."'2 The use of intrathecal drug delivery systems (IDDSs) is most common for patients with spine disorders (post-laminectomy syndrome, compression fractures, spinal stenosis, spondylosis, and spondylolisthesis) or non-spine-related pain disorders (complex regional pain syndrome, rheumatoid arthritis, connective tissue disorders, and chronic pancreatitis). ${ }^{3,4}$

IDDSs are highly complex systems. The IDDS is composed of a pump that stores the drug in a refillable reservoir and delivers it to the IT space via a catheter. A replaceable battery powers the drug delivery, and an external device programs drug delivery parameters. Successful clinical implementation requires significant physician training. Training involves surgical training for implantation, training for interrogating and programing pumps, training for maintenance and refilling of pumps, and imparting knowledge of complications that can occur at any time during the use of the IDDS. 
Despite the increased complexity, there are many benefits of IT over oral routes. By changing the route to IT, the production of morphine metabolites is greatly reduced. ${ }^{5}$ High concentration of metabolites can cause cognitive deficits and impaired attention and memory. ${ }^{6,7}$ An additional benefit is that the IT route delivers morphine in close proximity to the primary site of analgesia: opioid receptors in the spinal cord. ${ }^{8,9}$ Therefore, patients also experience fewer side effects due to the reduced IT opioid dose required for effective analgesia.

Despite widespread use of IDDS for chronic pain, limited high-quality clinical studies exist. Many systemic reviews using variable methods and inclusion criteria have sought to evaluate the evidence for IDDS. Although the conclusions were variable, the one common claim was that a paucity of trials exists. One systematic review concluded that evidence for IDDS was moderate and another concluded that evidence was limited. ${ }^{10,11}$ Guidelines for interventional techniques combined three systematic reviews to show $25 \%$ relief in $56.3 \%$ of patients and $50 \%$ relief in $40.8 \%$ of patients. $^{2}$ Since the 1980s, the development of IDDS has come a long way including many new dosing regimens and the ability of patients to administer bolus doses themselves. But as past systematic reviews have called for more rigorous studies, the need now is even more crucial in light of the multitude of ways in which IDDS are used. This update will cover new IDDS devices, trialing and surgical techniques with emphasis on surgical site infection (SSI), and a novel infusion program: microdose infusion.

\section{Types of pumps}

The first commercially available implantable programmable pump was the Medtronic SynchroMed ${ }^{\circledR}$ pump originally released for cancer chemotherapy in 1988. The indications for treatment were expanded to both cancer- and non-cancerrelated pain in 1991. To date, the most commonly implanted pump is the Medtronic SynchroMed ${ }^{\circledR}$ II pump, which was released in July 2004. The pump reservoir is called a metal bellows reservoir. Within the metal housing is a bellow that contains the drug and surrounding the bellows is a pressurized gas. The pressurized gas exerts pressure on the bellow, which changes the volume depending on the volume of the drug present. The drug delivery is achieved with a batterypowered peristaltic pump (rollers compress tubing to advance the drug forward). Due to the pressurized gas component, this system will deliver a different drug amount in environmental conditions of high pressures such as high altitudes, scuba diving, and hyperbaric chambers - or in conditions of high temperatures such as in hot tubs and saunas. Therefore, the patient is advised to avoid these conditions.

Medtronic has added an external device, personal therapy manager $\left(\right.$ myPTM $\left.^{\circledR}\right)$, which the patient can use to activate the SynchroMed ${ }^{\circledR}$ infusion system to give a bolus in addition to the continuous infusion. This addition allows patient to customize their pain control to cover variations in chronic pain. The myPTM ${ }^{\circledR}$ can be programed by the physician to the bolus dose, the lockout time, and the total number of doses a patient can receive per day. A European study examined the short-term pain control and satisfaction in 45 patients over 5 weeks. ${ }^{12,13}$ The patients found the myPTM $^{\circledR}$ easy to use and instructions easy to understand. The myPTM ${ }^{\circledR}$ provides audible and visual feedback indicating successful activation of a bolus. In all, 95\% of patients found the feedback useful. Whereas the visual analog scale (VAS) was unchanged during the 5-week period, the major benefit was patient satisfaction. The optima study examined pain relief and patient satisfaction of 168 patients using myPTM ${ }^{\circledR}$ over 12 months. Roughly half of the patients had preexisting pump and the other half received pumps at the start of the study. At 12 months, the overall average VAS was reduced by $29 \%$ compared to baseline. There was a trend to decrease the use of other pain medications, and the quality of life improved slightly. A majority of patients (85\%) felt more satisfied with the myPTM ${ }^{\circledR}$. Both studies found the myPTM $^{\circledR}$ safe with the majority of myPTM $^{\circledR}$ malfunction due to failure of myPTM ${ }^{\circledR}$ telemetry with the pump. ${ }^{12,13}$ Some studies have suggested that the use of myPTM ${ }^{\circledR}$ on top of low continuous infusion should reduce opioid tolerance and thus dose escalation, but there are insufficient data to support this theory. ${ }^{14}$

In 2012, two new programmable pumps were approved by the US Food and Drug Administration: Prometra ${ }^{\circledR}$ and MedStream ${ }^{\mathrm{TM}}$. The Prometra ${ }^{\circledR}$ pump has a metal bellow reservoir system. But instead of a peristaltic pump, the Prometra ${ }^{\circledR}$ has a valve-gated pump. The drug delivery is achieved by a series of valves: an inlet valve and an outlet valve. The positive pressure from the reservoir pushes the drug through the open inlet valve and into a dosing chamber. Then the inlet valve closes, and the outlet valve opens delivering the drug. The manufacturer refers to this system as a precision dosing system because the environmental pressure and temperature changes do not cause as much fluctuations in dosing as with the peristaltic pumps. The MedStream ${ }^{\mathrm{TM}}$ pump also has a metal bellow reservoir system. A ceramic actuator that opens the valve when charged and closes the valve when discharged controls the drug delivery. Advantages of the MedStream ${ }^{\text {TM }}$ 
pump are that there are no gears, motors, or rotating parts to wear out.

\section{Trialing techniques}

A trial is done before implanting the pump to determine the success of IT morphine. Pretrial goals help determine success. These goals depend on the patient's chronic pain condition and comorbidities. The most common goals are pain relief, functional improvement, reduction of systemic opioid use, and possible mental status change. ${ }^{15}$ The definition of successful pain relief is $\geq 50 \%$ reduction in VAS. ${ }^{16}$

The British Pain Society and Polyanalgesic Consensus Conference (PACC) recommend that a trial should be performed before implant. ${ }^{15,17}$ The expert consensus guidelines of PACC utilize critical evaluation of existing data and clinical panel discussions to formulate recommendations for physicians. The 2012 PACC was an expanded version of the previous 2007 PACC and not only provided a summary of the pharmacology of IT analgesics but also included additional sections on trialing methods, morbidity and mortality of IT drugs, and catheter granulomas. ${ }^{18}$

IT morphine trialing techniques are variable. Morphine trials have consisted of either bolus or continuous dose delivered by an epidural or IT route. Some feel that continuous IT trials closely mimic the results of IDDS. There are advantages and disadvantages to each trialing method. The bolus mode of trialing drug delivery is less expensive requiring shorter hospital observation than continuous mode. The continuous mode increases the risk for infection and spinal cord damage. There is no evidence to support that one method is superior to another. The PACC guidelines strongly recommend at least 24-hour inpatient observation for trialing. ${ }^{15}$

Adjustment to oral and systemic opioids during, or before trialing, is highly variable. According to a PACC survey on IT infusion technique conducted with 15,000 physicians, $40 \%$ of them indicated that they significantly reduced and $22 \%$ discontinued oral and systemic opioids during continuous IT trial. ${ }^{15}$ A minority of physicians (15\%) discontinued oral and systemic opioids weeks before the trial, and 33\% of them made no changes before trialing. ${ }^{15}$ No single regimen has been shown to be superior to the other.

The typical IT morphine bolus dose was $1 \mathrm{mg} .{ }^{16,19}$ Others have based the dose on calculated morphine equivalent pretrial dose and gave $1 / 100$ or $1 / 200$ of that dose for the IT bolus trial. ${ }^{20}$ Continuous morphine doses ranged from 0.025 (microdose infusion, see Infusion section) to $11.28 \mathrm{mg} /$ day. ${ }^{21}$ Others used 1/300 of the calculated morphine equivalent dose as the continuous trial dose. ${ }^{22}$ All trials were well tolerated by patients, and no one method has been shown to be better than the other. ${ }^{15,23-25}$

Many physicians in the Texas area use a single shot bolus trialing method with 50-150 mcg morphine for a microdose or $1 \mathrm{mg}$ for a conventional dose. The patient is observed as an inpatient for 23 hours for side effects such as respiratory depression, urinary retention, pruritus, peripheral edema, nausea, and vomiting. Patients are encouraged to test their functional ability while in the hospital. Before discharge, pain relief, functional improvement, and the impact of side effects are assessed. Typically, patients follow up in 2-3 weeks after discharge to discuss the trial results and to assess potential success of permanent implant IDDS.

\section{Surgical techniques}

Surgical placement of an IDDS requires advanced training, meticulous planning, and diligence in keeping abreast of current guidelines. Physicians seeking further advanced training can obtain courses through manufacturers or pain conferences. In addition, manufacturers can also provide physician mentors to help physicians develop IDDS practice de novo.

A retrospective study examined the complication rates of 100 patients with IDDS over 12 years. The complications were categorized as surgical, pump, or catheter related, and the frequency was shown to be $10 \%, 35 \%$, and $65 \%$, respectively. The surgical complication was most commonly SSI, and all infections occurred between 20 days and 80 days after implantation. Pump-related complications included pump repositioning, infection, and battery exhaustion. Catheter-related complications included catheter dislocation, disconnection, leakage, occlusion, and granuloma formation at the catheter tip. ${ }^{26}$

This section highlights recent opinions and guidelines for surgical techniques emphasizing how to avoid complications.

\section{Preimplant planning}

The first step of a successful permanent IDDS implant is to plan the location and orientation of the pump, pocket, and incision with the patient. This preimplant appointment allows the patient to understand how to live with an IDDS. Patients should see and hold the pump. It gives them an understanding of size and weight. ${ }^{27}$ The majority of pumps implanted are either $40 \mathrm{~mL}$ or $20 \mathrm{~mL}$ Medtronic SynchroMed $^{\circledR}$ II pumps. The main differences between the two pumps are as follows. The $40 \mathrm{~mL}$ pump affords longer duration between refills, which would benefit those who 
will require high doses. The diameter of each pump is the same with a $6.5 \mathrm{~mm}$ increase in depth for the $40 \mathrm{~mL}$ pump. Another consideration is the weight. The $40 \mathrm{~mL}$ pump is $30 \mathrm{~g}$ heavier when it is full and has a total weight of $215 \mathrm{~g}$ (7.56 oz). This weight difference might be a considerable factor for patients who use ultralight weight electronics in their daily lives. Another major consideration is planning of pump placement. A majority of pumps are placed in the lower quadrant of the abdomen, which is an area large enough to accommodate the pump. ${ }^{27,28}$ The pump should not contact the iliac crest, pubis symphysis, or lower costal margins. ${ }^{27,28}$ The clearance of these bony borders should be checked with the patient sitting, standing, and lying supine. As the patient changes position, so does the protrusion of the abdomen, which may cause the pump to contact bone in one but not all patient positions. In addition to these anatomical constraints, the location of the patient's waistband should be marked in sitting and standing positions. These measurements minimize discomfort and possible pump damage.

In obese patients, the abdominal panniculus might overlay the lower abdominal area, and this might make the pump less accessible during pump refills, and during the delivery of bolus by the patient. In general, the patient might have increased discomfort. An alternative location is the posterior flank. The flank area not only avoids the overlying panniculus but also may have a thinner adipose layer, which will allow more superficial anchoring to fascia. Anchoring to the fascia is recommended rather than midway through the adipose layer, as it is much more secure thereby preventing the pump from flipping. ${ }^{28}$

The pump refill procedure should be explained to the patient. Additionally, an estimate of time between pump refills gives the patient an understanding of their future schedule of appointments. In order to facilitate pump refilling, the pump should be implanted no greater than $2.5 \mathrm{~cm}$ depth. ${ }^{28}$ This implantation depth is also important for being able to do the telemetry and reprograming.

The advanced planning not only improves patient satisfaction but also promotes an efficient implant surgery. For a review of the entire surgical implant techniques, the author recommends two textbooks: Neuromodulation and Intrathecal Drug Delivery for Pain and Spasticity. ${ }^{27,28}$ Each book has a chapter on surgical technique that includes a detailed description of the surgical steps.

Postoperative complications related to surgical technique include SSI, catheter-related complications, postdural puncture headache/cerebrospinal fluid leak/hygroma, pocket seroma/hematoma, wound dehiscence, or skin erosion.
The most common complication is SSI ranging from $2.4 \%$ to $7 \% .{ }^{29,30} \mathrm{~A}$ recent retrospective study examining SSI for 142 implantable pain devices found a positive correlation between surgical time and SSI. ${ }^{30}$ The location of SSI was found to be most frequently in the pump pocket. ${ }^{29,30}$ Studies specifically addressing SSI of implantable pain devices are severely limited, and most guidelines are based on studies in other surgical fields.

Prevention of SSI can be organized into preoperative, intraoperative, and postoperative techniques. Preoperative techniques involve optimizing the patient's risk factors for SSI. The most important causative factor in SSI is the patient. Many patient factors increase the risk of SSI such as glycemic control, skin and nasal flora, smoking, concurrent sites of infections, and immune status.

Poor glycemic control (serum blood glucose $>150 \mathrm{mg} / \mathrm{dL}$ ) has long been shown to be associated with higher rates of SSI in several different types of surgeries. In an updated recommendation for control of SSI, a maximal glucose target of $180 \mathrm{mg} / \mathrm{dL}$ was recommended. ${ }^{31}$ A recent study examining SSI in thoracic and lumbar instrumentation surgeries showed that patient with diabetes mellitus (DM) had a $16.7 \%$ chance of SSI and those without DM 3.2\%. Among the patients with DM, the average $\mathrm{HGbA}_{1 \mathrm{c}}$ was $7.6 \%$ in those who developed SSI compared to $6.9 \%$ in those who did not. Lowering the $\mathrm{HgbA}_{1 \mathrm{c}}$ to $<7.0 \%$ before surgery was recommended. ${ }^{32}$

A thorough physical examination looking for sites of chronic infections is critical. Chronic infections such as periodontal disease, sacral decubitus, and foot ulcerations are often ignored or underreported by patients. Natural skin flora should be reduced before surgery as well as screening for high counts of nasal Staphylococcus aureus. A high number of nasal carriers of $S$. aureus are usually asymptomatic and will only be detected by screening. A large multicenter trial showed a reduction from $7.7 \%$ to $3.4 \%$ in SSI with the preoperative treatment of intranasal mupirocin and skin decolonization with chlorhexidine. The reduction was most pronounced in the occurrence of deep SSI. Patients in the decolonization group applied mupirocin ointment 2\% (Bactroban, GlaxoSmithKline plc, London, UK) in both nares twice daily in combination with daily body washes with chlorhexidine gluconate soap, $40 \mathrm{mg} / \mathrm{mL}$ (HiBiScrub, Mölnlycke Health Care, Sweden) for 5 days. $^{33}$

Smoking has long been associated with delayed healing and increased SSI. This is especially true in plastic surgeries and might be similar for SSI of pump pockets but has not been established yet. A study examining SSI rate of smokers and 
non-smokers showed rates to be $12 \%$ and $2 \%$, respectively. It also showed that if the smokers abstained for 4 weeks before surgery, the rates of SSI were equal to that of nonsmokers. ${ }^{34}$

\section{Intraoperative techniques}

Good basic surgical techniques to obtain hemostasis, limiting tissue trauma, avoiding electrocautery at the superficial skin layers, and wound closure without tension are essential to a successful implanted pain device practice. These surgical skills will improve with experience and training.

Good basic antiseptic techniques include meticulous attention to surgical field skin preparation and draping. Skin preparation with chlorhexidine alcohol solutions has been shown to be superior to povidone-iodine solutions. ${ }^{35}$ The sterile draping should be wide so that the surgeon has acceptable access and will avoid repositioning the drape during the surgical procedure. Lifting the drape during surgery has been shown to increase infection rates by $66 \% .^{36}$ Prophylactic antibiotics should be given intravenously and within 30 minutes of skin incision. ${ }^{37}$ Normothermia should be maintained during and after surgery, as this time is critical for bacterial fixation, a bacterial transition from contamination to infection. A core temperature of $34.7^{\circ} \mathrm{C}$ has been shown to increase SSI by $300 \% .{ }^{38}$ Therefore, active warming devices for patients as soon as they enter the operating room are requested. In addition, two other factors have been raised in orthopedic spine surgeries that are applicable to implantable pain surgeries: sterility of the $\mathrm{C}$-arm drape and duration of hardware exposure in the operating room environment.

The C-arm drape is not as sterile as one might think and is another potential source of contamination. A study examining five different locations on 25 full-length $\mathrm{C}$-arm covers found that $96 \%$ of the locations were contaminated at the end of the surgery. ${ }^{39}$ Another study examining the timing of $\mathrm{C}$-arm contamination showed that $50 \%$ contamination occurred within 20 minutes from the start of surgery and $80 \%$ at 80 minutes. Despite the contamination, no correlation was shown between SSI and C-arm contamination. ${ }^{40}$ Both studies showed a correlation between the number of lateral positions and the contamination rate. Therefore, it is recommended not to touch the top of the C-arm as this area is most likely contaminated during lateral position and in general to minimize contact with the $\mathrm{C}$-arm drape. Further studies are needed to determine the source of contamination.

Pain physicians mostly focused on the surgical field but should also pay attention to the instrument table and specifically the handling of the pump. The pump is usually removed from the sterile packaging, prepared, and then implanted. A prospective study examining the SSI rate of 105 spine hardware cases found a reduction of SSI rate from $17 \%$ to $2 \%$ if the hardware was immediately covered with a sterile towel after removing the hardware from sterile packaging. ${ }^{41}$ Therefore, pain physicians should be mindful of implant exposure time and should keep implants covered as much as possible.

\section{Postoperative techniques}

Prevention of SSI continues into the postoperative period. Patient factors such as good glycemic control should continue. Close surveillance for wound infection is best accomplished with patient education on signs of infection and follow up in the clinic within 10 days. Occlusive dressing is not recommended for longer than 24-48 hours because after this time infection rates have been shown to increase. ${ }^{42,43}$

\section{Infusion programs Microdose infusions}

Recently, a novel method of transitioning to IT morphine was described. Patients were weaned off all oral opioids and maintained on an opioid-free period weeks before initiating IT therapy. ${ }^{21,44}$ The opioid wean and abstinence periods are thought to improve the success of IT morphine and to reverse tolerance. The second innovation was that the doses were much lower than traditional doses, with the average morphine dose $6 \mathrm{mg} /$ day. Two methods have been published. Grider weaned his patients off oral medication and then maintained patients on a 6-week opioid-free period. The trial consisted of a placement of an IT catheter with an external pump and continuous infusion as an inpatient. The initial infusion was started at $50 \mu \mathrm{g} /$ day and titrated every 12 hours until sufficient analgesia was achieved, usually in the $50-400 \mu \mathrm{g} /$ day range. Once efficacy was achieved, the patient was observed for 24-36 hours for side effects. Successful patients received permanent implantation 10-14 days later. ${ }^{21}$ Hamza et al weaned their patients off half of the oral medication before the IT trial. The remaining oral medications were completely weaned off and patients were maintained in an opioid-free period for 7-10 days before permanent implant. The IT trial was an inpatient repeat bolus through a temporary IT catheter. Each patient received three IT injections, either $0.25 \mathrm{mg}$ or $0.5 \mathrm{mg}$ morphine or saline, one each day for 3 days. Appropriate responses to the three injections determined a positive trial. ${ }^{44}$ The results of two studies showed satisfactory pain relief with limited dose escalation and no need for oral opioid supplementation. ${ }^{21,44}$ 
Physicians in the Texas area have modified this technique to include a more economical trial. The patients are weaned off of oral medications and maintained in an opioid-free period for 2-6 weeks. The trial is done as an outpatient. The patient receives 50-100 $\mu \mathrm{g}$ of IT morphine bolus either in the clinic or day surgery center and then is allowed to go home. The patients are instructed to not take any oral medication. A successful trial is considered to be a $50 \%$ pain reduction without side effects. Permanent implant occurs in 2-3 weeks. We have had no serious adverse effects. Most physicians describe the analgesia as equally effective or better than analgesia with oral medications. The major difference is a reduction of systemic side effects, most notably personality changes.

Although the idea and results sound promising, many are unsure of the theory as the management of IDDS and dose escalation is physician dependent. ${ }^{14}$ Others have commented that the success of this method is due to the requirement of an oral medication wean: a process that selects patients with a more productive, proactive mentality. Further studies are needed to determine optimal patient selection, opioid weaning period, and initial dose of IT morphine.

\section{Conclusion}

Technological advances, new IDDS manufacturers, patient-controlled devices, and infusion techniques continue to expand the options in IDDS. Unfortunately, the clinical pain field suffers from a lack of randomized controlled trials (RCTs). RCTs are the standard procedure for evidence-based medicine but are expensive and require extensive time commitment and funding. Most pain clinicians are unable to support RCTs. However, most can publish results and techniques by way of retrospective and prospective studies. These contributions are desperately needed.

Expert guidelines, such as PACC, provide a concise summary of clinical studies and expert opinion. This is an excellent source for physicians. The PACC also describes recent innovations, such as microdosing, and raises questions that are unanswered by current studies. Microdosing is a technique that deviates significantly from conventional practices and possibly will change the goals of analgesia, such as tracking personality changes. Continued refinement of guidelines and further studies will further accelerate growth in this field.

\section{Disclosure}

The author reports no conflicts of interest in this work.

\section{References}

1. Cherny N, Ripamonti C, Pereira J, et al. Strategies to manage the adverse effects of oral morphine: an evidence-based report. J Clin Oncol. 2001;19(9):2542-2554.

2. Manchikanti L, Abdi S, Atluri S, et al. An update of comprehensive evidence-based guidelines for interventional techniques in chronic spinal pain. Part II: guidance and recommendations. Pain Physician. 2013;16(Suppl 2):S49-S283.

3. GhafoorVL, Epshteyn M, Carlson GH, Terhaar DM, Charry O, Phelps PK. Intrathecal drug therapy for long-term pain management. Am J Health Syst Pharm. 2007;64(23):2447-2461.

4. Deer T, Winkelmuller W, Erdine S, Bedder M, Burchiel K. Intrathecal therapy for cancer and nonmalignant pain: patient selection and patient management. Neuromodulation. 1999;2(2):55-66.

5. Chauvin M, Samii K, Schermann JM, Sandouk P, Bourdon R, Viars P. Plasma pharmacokinetics of morphine after im, extradural and intrathecal administration. Br J Anaesth. 1982;54(8):843-847.

6. McCracken LM, Iverson GL. Predicting complaints of impaired cognitive functioning in patients with chronic pain. $J$ Pain Symptom Manage. 2001;21(5):392-396.

7. Sjogren $P$, Thomsen AB, Olsen AK. Impaired neuropsychological performance in chronic nonmalignant pain patients receiving long-term oral opioid therapy. J Pain Symptom Manage. 2000;19(2):100-108.

8. Cousins MJ, Mather LE. Intrathecal and epidural administration of opioids. Anesthesiology. 1984;61(3):276-310.

9. Dickenson AH. Spinal cord pharmacology of pain. Br J Anaesth. 1995;75(2):193-200.

10. Hayek SM, Deer TR, Pope JE, Panchal SJ, Patel VB. Intrathecal therapy for cancer and non-cancer pain. Pain Physician. 2011;14(3): 219-248.

11. Falco FJ, Patel VB, Hayek SM, et al. Intrathecal infusion systems for long-term management of chronic non-cancer pain: an update of assessment of evidence. Pain Physician. 2013;16(Suppl 2):SE185-SE216.

12. Maeyaert J, Buchser E, Van Buyten JP, Rainov NG, Becker R. Patientcontrolled analgesia in intrathecal therapy for chronic pain: safety and effective operation of the model 8831 personal therapy manager with a pre-implanted synchromed infusion system. Neuromodulation. 2003;6(3):133-141.

13. Ilias W, le Polain B, Buchser E, Demartini L. Patient-controlled analgesia in chronic pain patients: experience with a new device designed to be used with implanted programmable pumps. Pain Pract. 2008;8(3): 164-170.

14. Hayek SM, Hanes MC. Intrathecal therapy for chronic pain: current trends and future needs. Curr Pain Headache Rep. 2014;18(1):388.

15. Deer TR, Prager J, Levy R, et al. Polyanalgesic Consensus Conference 2012: recommendations on trialing for intrathecal (intraspinal) drug delivery: report of an interdisciplinary expert panel. Neuromodulation. 2012;15(5):420-435; discussion 435.

16. Anderson VC, Burchiel KJ, Cooke B. A prospective, randomized trial of intrathecal injection vs epidural infusion in the selection of patients for continuous intrathecal opioid therapy. Neuromodulation. 2003;6(3): $142-152$.

17. The British Pain Society. Intrathecal drug delivery for the management of pain and spasticity in adults; recommendations for best clinical practice. London: The British Pain Society; 2008. Available from: http:// www.britishpainsociety.org/book_ittd_main.pdf. Accessed September 23, 2014.

18. Deer TR. Polyanalgesic Consensus Conference 2012. Neuromodulation. 2012;15(5):418-419.

19. Kumar K, Kelly M, Pirlot T. Continuous intrathecal morphine treatment for chronic pain of nonmalignant etiology: long-term benefits and efficacy. Surg Neurol. 2001;55(2):79-86. discussion 86-78.

20. Rauck RL, Cherry D, Boyer MF, Kosek P, Dunn J, Alo K. Long-term intrathecal opioid therapy with a patient-activated, implanted delivery system for the treatment of refractory cancer pain. J Pain. 2003;4(8):441-447. 
21. Grider JS, Harned ME, Etscheidt MA. Patient selection and outcomes using a low-dose intrathecal opioid trialing method for chronic nonmalignant pain. Pain Physician. 2011;14(4):343-351.

22. Kim D, Saidov A, Mandhare V, Shuster A. Role of pretrial systemic opioid requirements, intrathecal trial dose, and non-psychological factors as predictors of outcome for intrathecal pump therapy: one clinician's experience with lumbar postlaminectomy pain. Neuromodulation. 2011;14((2):165-175; discussion 175.

23. Deer TR, Levy R, Prager J, et al. Polyanalgesic Consensus Conference 2012: recommendations to reduce morbidity and mortality in intrathecal drug delivery in the treatment of chronic pain. Neuromodulation. 2012;15(5):467-482; discussion 482.

24. Deer TR, Prager J, Levy R, et al. Polyanalgesic Consensus Conference 2012: recommendations for the management of pain by intrathecal (intraspinal) drug delivery: report of an interdisciplinary expert panel. Neuromodulation. 2012;15(5):436-464; discussion 464-466.

25. Deer TR, Prager J, Levy R, et al. Polyanalgesic Consensus Conference - 2012: consensus on diagnosis, detection, and treatment of catheter-tip granulomas (inflammatory masses). Neuromodulation. 2012;15(5):483-495; discussion 496.

26. Fluckiger B, Knecht H, Grossmann S, Felleiter P. Device-related complications of long-term intrathecal drug therapy via implanted pumps. Spinal Cord. 2008;46(9):639-643.

27. Rosenow JM. Surgical techniques for intrathecal medication delivery system implantation. In: Krames ES, Peckham PH, Rezai AR, editors. Neuromodulation. London: Elsevier; 2009:1027-1032.

28. Buvanendran A, Jaycox M, Deer TR. Techniques of implant placement for intrathecal pumps. In: Deer TR, editor. Intrathecal Drug Delivery for Pain and Spasticity. Vol 2. Philadelphia: Saunders; 2012:78-83.

29. Follett KA, Naumann CP. A prospective study of catheter-related complications of intrathecal drug delivery systems. J Pain Symptom Manage. 2000;19(3):209-215.

30. Engle MP, Vinh BP, Harun N, Koyyalagunta D. Infectious complications related to intrathecal drug delivery system and spinal cord stimulator system implantations at a comprehensive cancer pain center. Pain Physician. 2013;16(3):251-257.

31. Alexander JW, Solomkin JS, Edwards MJ. Updated recommendations for control of surgical site infections. Ann Surg. 2011;253(6): 1082-1093.
32. Hikata T, Iwanami A, Hosogane N, et al. High preoperative hemoglobin $A_{1 c}$ is a risk factor for surgical site infection after posterior thoracic and lumbar spinal instrumentation surgery. J Orthop Sci. 2014;19(2):223-228.

33. Bertrand X, Slekovec C, Talon D. Preventing surgical-site infections in nasal carriers of Staphylococcus aureus. N Engl J Med. 2010;362(1): 9-17.

34. Sorensen LT, Karlsmark T, Gottrup F. Abstinence from smoking reduces incisional wound infection: a randomized controlled trial. Ann Surg. 2003;238(1):1-5.

35. Darouiche RO, Wall MJ Jr, Itani KM, et al. Chlorhexidine-alcohol versus povidone-iodine for surgical-site antisepsis. $N \mathrm{Engl} \mathrm{J} \mathrm{Med}$. 2010;362(1):18-26.

36. Alexander JW, Aerni S, Plettner JP. Development of a safe and effective one-minute preoperative skin preparation. Arch Surg. 1985;120(12): 1357-1361.

37. Rosenberg AD, Wambold D, Kraemer L, et al. Ensuring appropriate timing of antimicrobial prophylaxis. J Bone Joint Surg Am. 2008;90(2): 226-232.

38. Kurz A, Sessler DI, Lenhardt R. Perioperative normothermia to reduce the incidence of surgical-wound infection and shorten hospitalization. Study of Wound Infection and Temperature Group. $N$ Engl J Med. 1996;334(19):1209-1215.

39. Biswas D, Bible JE, Whang PG, Simpson AK, Grauer JN. Sterility of C-arm fluoroscopy during spinal surgery. Spine (Phila PA 1976). 2008;33(17):1913-1917.

40. Peters PG, Laughlin RT, Markert RJ, Nelles DB, Randall KL, Prayson MJ. Timing of C-arm drape contamination. Surg Infect (Larchmt). 2012;13(2):110-113.

41. Bible JE, O’Neill KR, Crosby CG, Schoenecker JG, McGirt MJ, Devin CJ. Implant contamination during spine surgery. Spine J. 2013;13(6): 637-640.

42. Hutchinson JJ, Lawrence JC. Wound infection under occlusive dressings. J Hosp Infect. 1991;17(2):83-94.

43. Hutchinson JJ, McGuckin M. Occlusive dressings: a microbiologic and clinical review. Am J Infect Control. 1990;18(4):257-268.

44. Hamza M, Doleys D, Wells M, et al. Prospective study of 3-year follow-up of low-dose intrathecal opioids in the management of chronic nonmalignant pain. Pain Med. 2012;13(10):1304-1313.
Journal of Pain Research

\section{Publish your work in this journal}

The Journal of Pain Research is an international, peer-reviewed, open access, online journal that welcomes laboratory and clinical findings in the fields of pain research and the prevention and management of pain. Original research, reviews, symposium reports, hypothesis formation and commentaries are all considered for publication.

\section{Dovepress}

The manuscript management system is completely online and includes a very quick and fair peer-review system, which is all easy to use. Visit http://www.dovepress.com/testimonials.php to read real quotes from published authors. 